\title{
The negative reinforcing functions of nonconformity*
}

\author{
JEFFREY A. SEYBERT and ROBERT FRANK WEISS \\ University of Oklahoma, Norman, Oklahoma 73069
}

\begin{abstract}
Employing the general approach which Neal Miller called "extension of liberalized S-R theory," two experiments $(N=108)$ found that $\mathrm{Ss}$ would learn an instrumental response, the reinforcement for which was the opportunity to escape from a situation in which they were a nonconformist. When the nonconformity situations were presented on an intermittent basis, speed of the response was found to be a function of the percentage of nonconformity trials $(p<.001)$. When the opportunity to escape was delayed $(0,1.5$, or $3 \mathrm{sec})$, response acquisition was found to be an inverse function of the length of the delay $(\mathrm{p}<.001)$. The results of both experiments correspond to data collected in instrumental escape conditioning experiments on delay of reinforcement and intermittent shock using similar procedures.
\end{abstract}

A number of investigators have shown that conformity and nonconformity behaviors may be analyzed within a conditioning framework (e.g., Endler, 1965, 1966; Endler \& Hoy, 1967; Jones, Wells, \& Torrey, 1958; Tolman \& Barnsley, 1966; Walker \& Heyns, 1966). These authors, using conformity and nonconformity behaviors as dependent variables, have demonstrated that these behaviors may be modified by reinforcement. While the above studies have examined the causes of conformity-nonconformity behaviors, it may also be possible to investigate the effects of a conformity or nonconformity situation on other behaviors. Thus, as well as being a class of behaviors which may be learned and modified, it is possible that conformity-nonconformity situations may, for example, serve to reinforce other instrumental responses. This type of experimental approach, i.e., the use of some social situation or process as a reinforcer for some nonsocial instrumental response, has been used with success in a number of experimental paradigms, e.g., conversational behavior (Weiss, Boyer, Colwick, \& Moran, 1971; Weiss, Lombardo, Warren, \& Kelley, 1971) and altruistic behavior (Weiss, Buchanan, Altstatt, \& Lombardo, 1971; Weiss, Boyer, Lombardo, and Stich, 1973). It is the specific purpose of the present research to assess the reinforcing functions, if any, of escape from a situation wherein an individual is a nonconformist.

In order for such a process to operate, a person must be able to discriminate conformity from nonconformity situations. Miller and Dollard (1941) have shown that Ss can learn to discriminate between the cues of sameness and difference of their own behavior to that of others. Such cues may be extremely subtle in the mastery of complex skills, but in the present experiments the cues of sameness and difference were easily discriminable. In the course of socialization "a large number of punishments for being different establish fear of

*This research was supported in part by Grant GS27652 from the National Science Foundation to R. F. Weiss. Requests for reprints may be sent to either author, Department of Psychology, University of Oklahoma, Norman, Oklahoma 73069. nonconformity ... While learning to talk the child receives training in matching words, sentences, and descriptive paragraphs with important features of the environment. He is corrected for mistakes and learns to have anxiety about responding differently from other people... the cues of difference arouse anxiety [Dollard \& Miller, 1950, p. 92, 119]." Moreover, a wide variety of reference groups such as families, clans, trade inions, and nation-states require a certain degree of zonformity to group norms from their members. Of course, a given reference group may positively reward conformity to group norms and react to nonconformity not with punishment but with mere nonreward, as in the familiar experimental paradigm of selective learning. But in selective learning the nonrewarded alternative acquires the characteristics of an aversive drive from which the $S$ will learn to escape (Daly, 1971; Terrace, 1971), and similar characteristics might be exhibited by a nonconformist alternative. The negative reinforcing functions of nonconformity should thus be a fundamental psychological phenomenon, extending over a wide variety of situations, and deserving of rigorous experimental study. Experimental evidence that differences in opinion arouse aversive drive can be found in such diverse situations as the classical conditioning of attraction responses (e.g., Byrne, 1971; Byrne \& Clore, 1967), the differential energization of dominant and subordinate habits in paired-associates learning (Lombardo, Libkuman, \& Weiss, 1972), and the instrumental escape conditioning of a switch-throwing response in verbal communication (e.g., Weiss, Boyer, Colwick, \& Moran, 1971; Weiss, Lombardo, Warren, \& Kelley, 1971). As the theoretical analysis developed above suggests, arousal of aversive drive by the cues of difference could apply with particular force to nonconformity. It should be possible, then, to reinforce an instrumental response by removing the $S$ from the situation where he is a nonconformist. This type of procedure is analogous to an instrumental escape conditioning paradigm in animal learning. The experiments reported here attempted a stringent test of the hypothesis that a nonconformity situation is 
analogous to instrumental escape conditioning by studying analogs of intermittent shock, delay of reinforcement, acquisition trials, and the Delay by Trials interaction, employing measures and procedures similar to escape conditioning.

\section{GENERAL METHOD}

The present experiments represent an attempt to delineate the negative reinforcing functions of nonconformity and are not intended to duplicate naturalistic nonconformity situations in all their richness and complexity. A laboratory experiment is not designed to duplicate nature perfectly, but rather is to be used as a tool to investigate the basic processes underlying natural phenomena.

The procedure involved in the present experiments inverts the type of perceptual judgment technique used by Asch (1951, 1956). On each trial the $S$ recorded a perceptual judgment, saw that he was disagreed with by a number of other "Ss" (i.e., was a nonconformist) and then pressed a switch (the instrumental response), the reinforcement for which was escape from the aversive (nonconforming) situation.

The present research differs from "classical" studies of conformity-nonconformity (e.g., Asch, 1951) in that in those studies the S was given a "choice" of whether or not to conform, whereas in the present experiments the Ss, as a result of the procedure, were placed in a position of nonconformity. This distinction is not unlike that between selective learning in a T-maze and instrumental conditioning in a straight alley, and thus the present procedure offers a novel method of examining the possible effects of nonconformity. In "real life," nonconformity may arise through neglect, failure, or refusal to conform, and thus having the $S$ make his judgment first in the present experiments was simply a device which permitted experimental control of failure to conform.

\section{Deception and Masking Task}

A deception was used to mask the instrumental response and reinforcement contingencies from the Ss (Spence, 1966). The experiments were represented to the $\mathrm{Ss}$ as studies of psychological insight. "You are participating in an experiment which involves measures of psychological insight. It is well know that psychotherapists use the facial expressions of their patients to aid them in assessment and interpretation of certain types of emotional imbalance... It has been established that information such as this can be obtained from live interviews or movies... It is the purpose of this experiment to find out if such information can be gathered by college students using still photographs." As a masking task the $\mathrm{S}$ was told that the apparatus was only partly automated and that part of his job was to watch the choices of five other "Ss" as they appeared on his panel so that he could push a corresponding button to register their choices in a memory bank, and then press a switch to clear the memory bank for the next series of choices. The pseudochoices of the other five "Ss" were provided by $\mathrm{E}$ and a majority of the "Ss" either agreed or disagreed with the $S$ depending upon the experimental contingencies. The switch pressing (the instrumental response) erased all six choices and effectively removed the $S$, at least temporarily, from the situation in which he was a nonconformist. A second introductory psychology student participated along with the $S$ and sat at an experimental panel in a cubicle adjacent to the S's cubicle, but this second person's choices were not recorded since he was present only to increase the face validity of the procedure for the $S$ and for potential Ss in the $S$ pool. The other four participants were present only on the S's memory bank and on the E's control panel.

\section{Apparatus}

The $S$ wore headphones and was seated in front of an experimental panel. Labels on the S's panel were stated in terms of the masking task instructions. Since the "Ss' Choices" were made between pairs of pictures labeled " $A$ " and " $B$," several of the devices mounted on the panel were also labeled " $A$ " and "B": (1) a pair of lights labeled "Ss' Choices," (2) corresponding pushbuttons labeled "Transfer to Memory," and (3) a"Memory Bank" with an ostensible readout consisting of a column of six pairs of square lights, one pair for each "S." Also mounted on S's panel were a "Subject 1 Go" signal, a light labeled "Memory Being Recorded," and a light labeled "OK to Erase Memory" with a corresponding "Erase Memory" switch.

The E's control panel was located in the room adjacent to that occupied by the S. The control panel consisted of a series of switches to control the pseudochoices and the lights of the S's "memory bank." Also in the control panel were cassette recorders for playing instructions, a microphone, a set of headphones for the E, a control timer, and a Lafayette digital stop lock which automatically measured the S's response latency to $.01 \mathrm{sec}$.

\section{Procedure}

The $S$ received the deceptive rationale and preexperimental instructions on tape over the headphones. The $E$ then asked all six "Ss" if they had any questions.

An experimental session consisted of 15 trials, and the series of clearly labeled signals led each $\mathrm{S}$ easily through each trial. An experimental trial began when the tape briefly described the "mental or emotional problem" suffered by an unidentified member of the pair (A and B) pictured on that trial. When the "Subject-1 Go" light was lit, the $S$ identified the member described by pressing the corresponding pushbutton (A or B) which simultaneously transferred his choice to the "memory bank." Because $S$ was the first to choose, it was possible to make him a nonconformist by manipulation of the other Ss' choices as presented to $\mathrm{S}$ via the "Ss' Choices" lights (A or B). It was desirable to focus the attention of $S$ directly on his nonconformity to the other "Ss" pseudochoices. Attention to the other Ss' choices was maximized by S's extra job of pressing the corresponding (A or B) "Transfer to Memory" button, and, after all six choices had been transferred to the "mem ory bank," $S$ was required to monitor the "Memory Being Recorded" light, which was placed so as to provide him with a good view of his nonconformity displayed by the memory bank lights. Thus, the task was designed so that the $\mathrm{S}$ necessarily directed his attention to his nonconformity in order to perform the experimental task. Since $\mathrm{E}$ could monitor these actions, it was possible to be certain that Ss were performing the tasks which directed their attention to their nonconformity. Nonconformity trials placed the $S$ in a minority of one (himself) or two. No $S$ had a constant opposition, and indeed there were other trials included on a specified schedule in which $S$ was agreed with by three or four "Ss." Such trials were necessitated by the transparent duplicity of constant opposition, as well as the utility of such trials as an experimental manipulation.

Escape from nonconformity was afforded by the final steps. The "OK to Erase Memory" light went on, $S$ threw the "Erase Memory" switch, and the memory bank lights went out. The E's latency timer automatically started when S's "OK to Erase Memory" light went on and stopped when $S$ threw the "Erase Memory" switch. This procedure was modeled on discrete trial instrumental conditioning. The reinforcement (erasing the choices which indicated nonconformity) was contingent on the instrumental response (switch pressing). The dependent variable was speed ( $1 /$ latency) measured from the time of the presentation of the $S^{D}$ (illumination of the "OK to Erase Memory" light) to the instrumental switch-pressing response.

\section{EXPERIMENT I: INTERMITTENT NONCONFORMITY}

The intermittent shock procedure has received considerable experimental attention as a technique for studying instrumental escape conditioning (e.g., 
Franchina, 1966, 1969; Franchina \& Snyder, 1970). Intermittent shock involves the presence of shock on some conditioning trials and the absence of shock on others. Franchina (1966) found that acquisition performance, i.e., asymptotic response speed, was a function of the percentage of shock trials. If escape from a nonconformity situation is analogous to reinforcement, then speed of the resporse which produces the escape should be a function of the percentage of trials on which the $S$ was placed in a nonconformity situation. It would be expected that (a) a group receiving nonconformity trials $67 \%$ of the time would show greater asymptotic performance than a group receiving nonconformity trials $33 \%$ of the time, and (b) that the $33 \%$ group would show greater response speed than a group which received no nonconformity trials ( $0 \%$ group). The $0 \%$ group would be expected to demonstrate no increase in speed of the instrumental response since no drive, and thus no reinforcement, would be present.

\section{Method}

The Ss were 24 male and 24 female introductory psychology students who were participating in the experiment as part of a course requirement. They were equally divided into three groups $(N=16 /$ group): Group $67 \%$ received 10 nonconformity trials out of 15; Group 33\% received 5 nonconformity trials out of 15 ; and Group 0 received no nonconformity trials (i.e., Ss in this group were in the majority on all 15 trials). Four different mixed sequences of intermittent nonconformity were used, fully counterbalanced for sex.

\section{Results and Discussion}

It can be seen in Fig. 1 that the data from the present experiment closely parallel the intermittent shock-escape data of Franchina (1966) for Groups 67\% and 33\%. Specifically, Group $67 \%$ shows greater response speed than does Group 33\% and both Groups 67\% and 33\% show faster response speed and greater asymptotic performance than Group 0. In fact, there does not appear to have been any increase in response speed for Group 0 . All of these impressions were confirmed by a 3 (levels of intermittent nonconformity) by 2 (sex) by 15 (individual trials) analysis of variance which was performed on the data. The analysis revealed a significant intermittent nonconformity main effect $[F(2,42)=25.90, p<.001]$, a significant main effect for trials $[F(14,588)=9.31, p<.0011$, and a nonsignificant main effect for sex $(F<1)$. The Intermittent Nonconformity by Trials interaction was significant $[F(28,588)=2.50, p<.001]$, as was the Sex by Trials interaction $[F(14,588)=2.10, p<.05]$. Subsequent analyses of the Intermittent Nonconformity by Trials interaction (via Tukey's correction procedure) indicated that, over a block of the last four trials, Group $67 \%$ was responding significantly faster than Group 33\% ( $<<.05)$ and both Groups 67\% and 33\% were responding faster than Group $0(p<.01$ in both cases). Tests of simple main effects on the trials variable for each group indicated that significant increases in

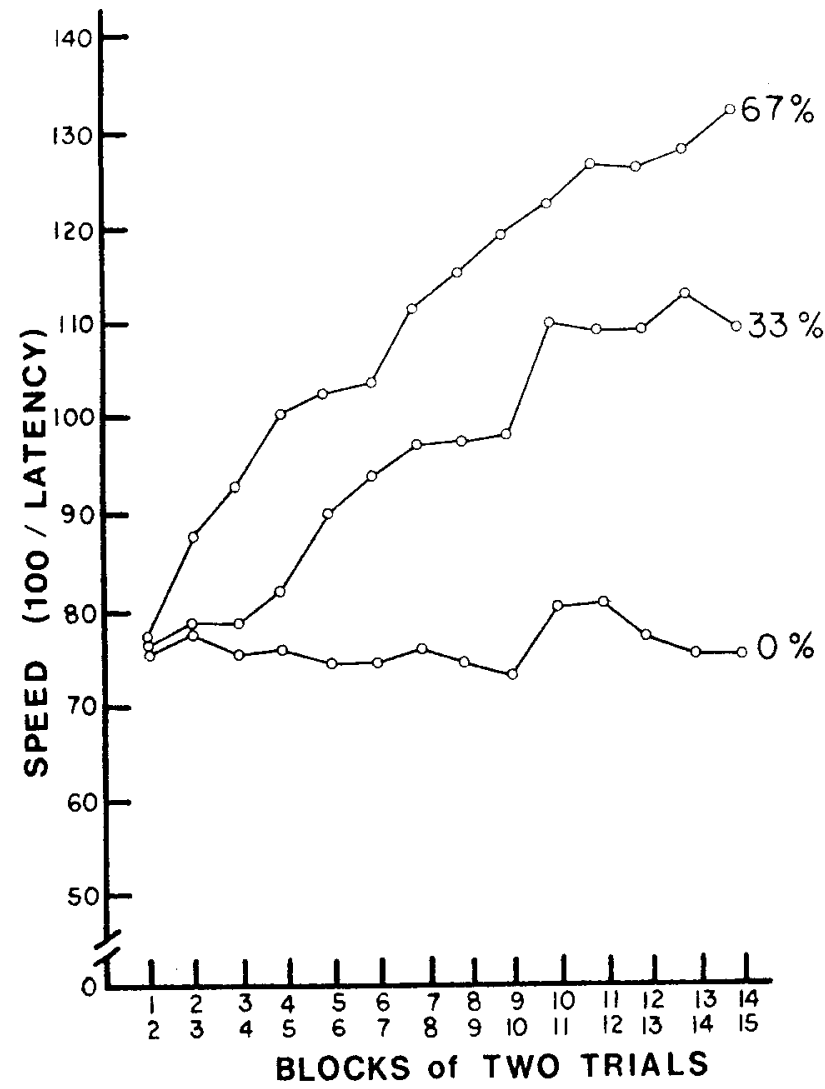

Fig. 1 Intermittent shock analog: Curves of response speed for three percentages of nonconformity trials.

response speed occurred in Group $67 \%$ $[F(14,210)=5.73, \quad p<.001]$ and in Group 33\% $[\mathrm{F}(14,210)=4.96, \mathrm{p}<.001]$, but that, as predicted, no increase in response speed occurred in Group 0 $[F(14,210)=.80]$. Even though the Sex by Trials interaction was significant, indicating that the different sexes responded at different rates, the fact that the Intermittent Nonconformity by Sex interaction $(F<1)$ failed to approach an acceptable level of significance indicates that intermittent nonconformity was not differentiallv affected by the sex variable.

Thus, the results indicated (a) that escape from a nonconformity situation does function to reinforce the response that resulted in the escape from nonconformity, (b) that increase in response speed is a function of the percentage of nonconformity trials, and (c) that when no "drive" aroused by nonconformity is present (Group 0\%), no increase in speed of the response occurs. Since the data of the present experiment (for Groups $66 \%$ and $33 \%$ ) closely parallel that of Franchina (1966), support is provided for the hypothesis that the nonconformity situation is analogous to instrumental escape conditioning.

\section{EXPERIMENT II: DELAY OF REINFORCEMENT}

If the opportunity to escape from a nonconformity situation functions as a reinforcer, then the time interval 
between the instrumental switch-pressing response and the darkening of the light in the memory bank which indicate nonconformity should have the functional properties of delay of reinforcement in instrumental escape conditioning. One property of delay of reinforcement is that response speed is an inverse function of length of delay, i.e., the longer the delay period, the weaker the response strength (e.g., Fowler \& Trapold, 1962; Penney, 1967; Woods \& Feldman, 1966). A second property of delay is that it interacts with trials: Delay effects are greater as the number of acquisition trials increases. Similar results should be expected with the present nonconformity procedure if escape from nonconformity functions as a reinforcer.

\section{Method}

There were three groups in the experiment representing three different levels of delay of reinforcement: $0,1.5$, and $3 \mathrm{sec}$. Each group was composed of 12 male and 8 female introductory psychology students who were participating to fulfill a course requirements (total $\mathrm{N}=60$ ). All groups received 15 trials, 10 of which were nonconformity trials. The sequence of trials was obtained from the same random schedule used in Experiment $I$. The delay of reinforcement was regulated automatically by an interval timer started by the S's switch-pressing response, which erased the lights in the memory bank after the prescribed delay period.

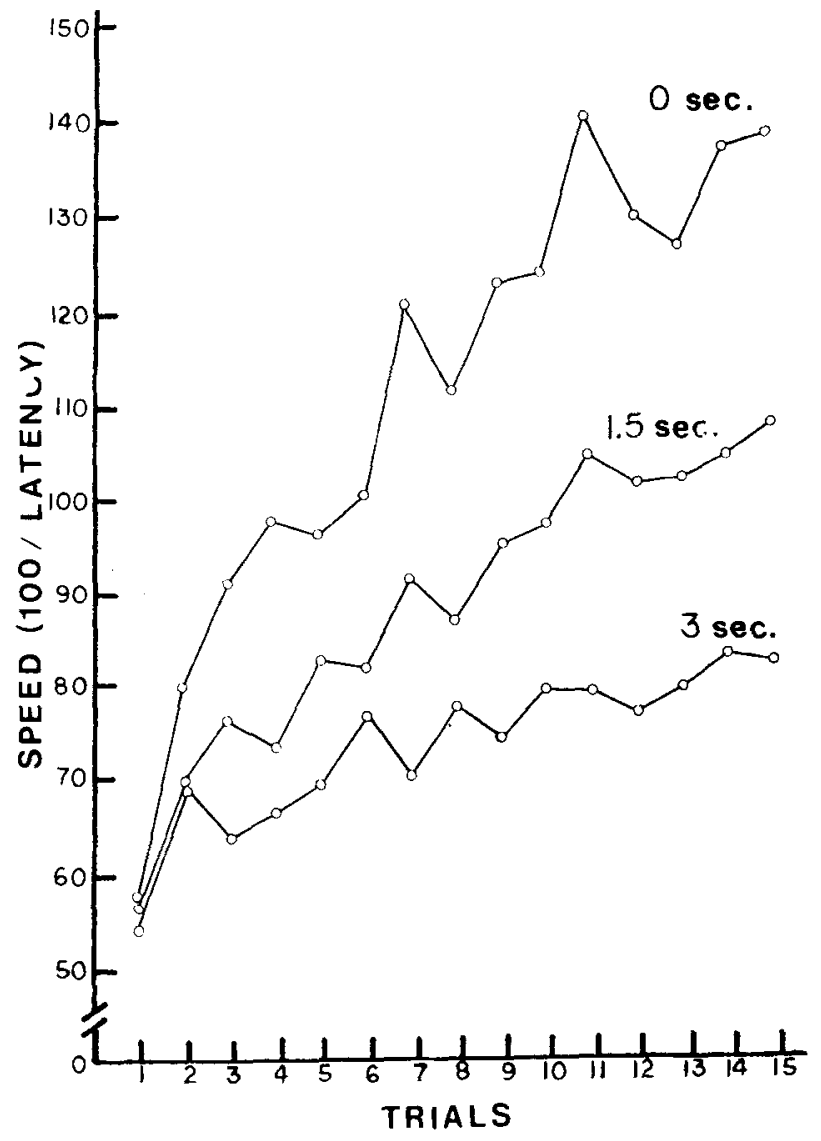

Fig. 2. Delay of reinforcement analog: Curves of response speed for three levels of delay of escape from nonconformity.

\section{Results and Discussion}

Figure 2 depicts nonconformity effects characteristic of delay of reinforcement. A 3 (level of delay) by 15 (trials) analysis of variance revealed significant main effects for trials $[F(14,798)=29.74, p<.001]$ and delay $[F(2,57)=32.53, p<.001]$. The Delay by Trials interaction was also highly significant $[F(28,798)=$ $3.34, p<.001]$. The Tukey post hoc comparisons indicated that response speed over the last four trials for the 0 -sec groups was significantly greater than for the $1.5-\mathrm{sec}$ group $(\mathrm{p}<.01)$ and that both the $0-\mathrm{sec}$ and $1.5-\mathrm{sec}$ groups were responding faster than the 3 -sec group ( $\mathrm{p}<.01$ in both cases). Tests of simple main effects on the trials variable for all groups revealed that all three groups demonstrated an increase in speed of the instrumental response across trials $[F(14,266)=13.55$, $16.17,3.90$, all ps $<.001$ for Groups $0 \mathrm{sec}, 1.5 \mathrm{sec}$, and $3 \mathrm{sec}$, respectivelyl. Both of the properties of delay of reinforcement described for instrumental escape conditioning, namely, the interaction of Delay by Trials and the fact that response speed is an inverse function of length of delay, were demonstrated in the present experiment using a nonconformity situation as the aversive motivational stimulus. Thus the results of the present experiment clearly indicated a correspondence between the nonconformity situation and escape conditioning.

\section{GENERAL DISCUSSION}

The results of both Experiments I and II provide strong support for the hypothesis that the nonconformity situation is analogous to instrumental escape conditioning. The present experiments indicated that escape from a situation in which one is a nonconformist functions like a reinforcer in escape conditioning. It was shown that Ss would learn an instrumental response, the reinforcement for which was the opportunity to escape from a situation in which they were a nonconformist. When the nonconformity situation was presented on an intermittent basis, response speed was found to be a function of the percentage of nonconformity trials. When the opportunity to escape nonconformity was delayed, response speed was found to interact with trials. These results correspond closely with those of escape conditioning experiments using the intermittent shock and delay procedures.

The results of the present experiments join a growing body of social psychological research modeled on instrumental conditioning, e.g., conversational behavior (Weiss, Boyer, Colwick, \& Moran, 1971; Weiss, Lombardo, Warren, \& Kelley, 1971), altruistic behavior (Weiss, Buchanan, Altstatt, \& Lombardo, 1971; Weiss, Boyer, Lombardo, \& Stich, 1973), and social facilitation (Weiss \& Miller, 1971). It is important to note that while the present research was modeled on escape 
conditioning, in no way is it proposed that nonconformity behavior is escape conditioning. Reduction is not the goal of this research but rather an attempt has been made to investigate a less known and understood research area (nonconformity) through use of a model (escape conditioning) which is much better understood, both in terms of empirical results and theoretical principles. A more complete exposition of the use of modeling as a technique for research guidance and theory construction may be found elsewhere (e.g., Weiss, Lombardo, Warren, \& Kelley, 1971; Weiss \& Miller, 1971).

Our principal purpose in conducting these experiments has been to further what Neal Miller (1959) calls "extension of liberalized S-R theory," broadening experimental psychology without sacrificing the principles or methodology or rigor of the discipline. In order to implement this purpose we have not sought further evidence that conformity is a learnable response but rather have taken the novel course of experimental investigation of the reinforcing functions of escape from nonconformity. As in all basic experimental psychology, the present experiments were intended to yield fundamental results, and a certain sophistication is always required in generalizing such fundamental results beyond the purity of the experimental laboratory, whether one studies verbal learning or studies nonconformity in an escape conditioning paradigm. The present experiments have revealed several such fundamental reinforcing properties of escape from nonconformity in a highly controlled experimental situation.

\section{REFERENCES}

Asch, S. E. Effects of group pressure upon the modification and distortion of judgments. In $\mathrm{H}$. Guetzkow (Ed.), Groups, leadership, and men, Pittsburgh: Carnegie Press, 1951.

Asch, S. E. Studies of independence and conformity: I. A minority of one against a unanimous majority. Psychological Monographs, 1956,70(Whole No. 416).

Byrne, D. The attraction paradigm. New York: Academic Press, 1971.

Byrne, D. Attitudes and attraction. In L. Berokowitz (Ed.), Aduances in experimental social psychology, Vol. 4. New York: Academic Press, 1969.

Byrne, D., \& Clore, G. L., Jr. Effectance arousal and attraction. Journal of Personality \& Social Psychology Monograph, 1967, 6(Whole No. 638).

Daly, H. B. Evidence for frustration during discrimination learning. Journal of Experimental Psychology, 1971, 88, 205-215.
Dollard, J., \& Miller, N. E. Personality and psychotherapy, New York: McGraw-Hill, 1950.

Endler, N. S. The effects of verbal reinforcement on conformity and deviant behavior. Journal of Social Psychology, 1965, 66 , 147-154.

Endler, N, S, Conformity as a function of different reinforcement schedules. Joumal of Personality \& Social Psy chology, 1966, 4, 175-180.

Endler, N. S., \& Hoy, E. Conformity as related to reinforcement and social pressure. Journal of Personality \& Social Psychology, 1967, 7, 197-202.

Fowler, H., \& Trapolod, M. A. Escape performance as a function of delay of reinforcement. Journal of Experimental Psychology, 1962, 63, 464-467.

Franchina, J. J. Effects of shock schedules on the acquisition and extinction of escape behavior. Psychonomic Science, $1966,4,277-278$.

Franchina, J. J. Intertrial intervals and shock schedules in escape training. Journal of Comparative \& Physiological Psychology, $1969,67,504-509$.

Franchina, J. J., \& Snyder, C. R. Effect of patterns of shock and nonshock training trials on response alternation and extinction in escape training. Psychonomic Science, 1970, 21, 177-179.

Jones, E. E., Wells, H. H., \& Torrey, R. Some effects of feedback from the experimenter on conformity behavior. Journal of Abnormal \& Social Psy chology, 1958, 57, 207-213.

Lombardo, J.,P., Libkuman, T. M., \& Weiss, R. F. The energizing effects of disagreement-induced drive. Journal of Experimental Research in Personality, 1972, 6, 133-141.

Miller, N. E. Liberalization of basic S-R concepts: Extensions to conflict behavior, motivation and social learning. In $\mathrm{S}$. Koch (Ed.), Psychology: A study of a science. Vol 2. General systematic formulations, learning and special processes. New York: McGraw-Hill, 1959

Miller, N. E., \& Dollard, J. Social learning and imitation. New Haven: Yale University Press, 1941.

Penney, R. K. Children's escape performance as a function of schedules of delay of reinforcement. Journal of Experimental Psy chology, 1967, 73, 109-112.

Spence, K. W. Cognitive and drive factors in the extinction of the conditioned eye-blink in human subjects.Journal of Experimental Psychology, 1966, 73, 445-458.

Terrace, H. S. Excape from S-O. Learning \& Motivation, 1971, 2, 148-163.

Tolman, C. W., \& Barnsley, R. H. Effects of verbal reinforcement on conformity and deviant behavior: Replication report. Psychological Reports, 1966, $19,910$.

Walker, E. L., \& Heyns, R. W. An anatomy for conformity. Englewood Cliffs, N. J: Prentice-Hall, 1962.

Weiss, R. F., Boyer, J. L., Colwick, J. T., \& Moran, D. J. A delay of reinforcement gradient and correlated reinforcement in the instrumental conditioning of conversational behavior. Journal of Experimental Psychology, 1971, 90, 33-38.

Weiss. R. F.. Boyer, J. L., Lombardo, J. P., \& Stich, M. H. Altruistic drive and altruistic reinforcement. Journal of Personality \& Social Psychology, 1973, 25, 390-400.

Weiss, R. F., Buchanan, W., Altstatt, L., \& Lombardo, J. P. A ltruism is rew arding. Science, 1971, 171, 1262-1263.

Weiss, R. F., Lombardo, J. P., Warren, D. R., \& Kelley, K. A. The reinforcing effects of speaking in reply. Journal of Personality \& Social Psychology, 1971, 20, 186-199.

Weiss, R. F., \& Miller, F, G. The drive theory of social facilitation." Psychological Review, 1971, 78, 44-57.

Woods, P. J., \& Feldman, G. B. Combination of magnitude and delay of reinforcement in instrumental escape conditioning. Journal of Comparative \& Physiological Psychology, 1966, 62 149-151.

Received for publication March 18, 1974 accepted for publication April 16, 1974.) 